\title{
Is sarcopenic obesity superior to sarcopenia as a predicting indicator in patients with hepatocellular carcinoma following hepatic resection?
}

\author{
Shinji Itoh, Tomoharu Yoshizumi, Masaki Mori \\ Department of Surgery and Science, Graduate School of Medical Sciences, Kyushu University, Fukuoka, Japan \\ Correspondence to: Shinji Itoh, MD, PhD. Department of Surgery and Science, Graduate School of Medical Sciences, Kyushu University, 3-1-1 \\ Maidashi, Higashi-ku, Fukuoka 812-8582, Japan. Email: itoshin@surg2.med.kyushu-u.ac.jp. \\ Provenance and Peer Review: This article was commissioned by the Editorial Office, Hepatobiliary Surgery and Nutrition. The article did not undergo \\ external peer review. \\ Comment on: Kobayashi A, Kaido T, Hamaguchi Y, et al. Impact of Sarcopenic Obesity on Outcomes in Patients Undergoing Hepatectomy for \\ Hepatocellular Carcinoma. Ann Surg 2019;269:924-31.
}

Submitted Sep 05, 2019. Accepted for publication Sep 24, 2019.

doi: 10.21037/hbsn.2019.09.14

View this article at: http://dx.doi.org/10.21037/hbsn.2019.09.14

The most common primary cancer derived from the liver is hepatocellular carcinoma (HCC), and its incidence is increasing globally (1). Hepatic resection has been established as a safe and effective treatment in patients with HCC. However, the number of patients who develop recurrence after hepatic resection remains high (2). The body composition, which consists of the skeletal muscle mass and fat area, is an important used to determine the perioperative risk and prognosis in patients with cancer.

We read the article by Kobayashi et al. (3) recently published in Annals of Surgery titled "Impact of sarcopenic obesity on outcomes in patients undergoing hepatectomy for bepatocellular carcinoma", with great interest. The authors investigated the effect of sarcopenic obesity on the surgical outcomes of patients who underwent hepatic resection for HCC. They measured cross-sectional skeletal muscle area at the third lumbar vertebral region and the crosssectional visceral fat area at the umbilical level on computed tomography. The skeletal muscle index (SMI) was calculated using the cross-sectional areas of skeletal muscle normalized for height $\left(\mathrm{cm}^{2} / \mathrm{m}^{2}\right)$. The authors defined sarcopenia as an SMI of $<40.31 \mathrm{~cm}^{2} / \mathrm{m}^{2}$ in male patients and $<30.88 \mathrm{~cm}^{2} / \mathrm{m}^{2}$ in female patients, and they defined obesity as a visceral fat area of $\geq 100 \mathrm{~cm}^{2}$ in both sexes. They included 465 patients who had undergone hepatic resection for HCC. In total, 62 patients $(13.3 \%)$ had sarcopenia and $250(53.8 \%)$ had obesity. The body composition was classified as non-sarcopenic non-obesity in 184 patients (39.6\%), non-sarcopenic obesity in $219(47.0 \%)$, sarcopenic non-obesity in $31(6.7 \%)$, and sarcopenic obesity in 31 (6.7\%). They found that patients with sarcopenic obesity had a significantly lower 3-year recurrence-free survival (RFS) rate than patients with non-sarcopenic non-obesity ( $19.3 \%$ vs. $37.8 \%$, respectively; $\mathrm{P}=0.003)$. Moreover, a significant difference was found in overall survival (OS) between patients with non-sarcopenic non-obesity and those with sarcopenic obesity ( $61.0 \%$ vs. $45.6 \%$, respectively; $\mathrm{P}=0.002)$, and sarcopenic obesity was an independent unfavorable prognostic factor for RFS (HR, 2.031; 95\% CI, $1.233-3.222 ; \mathrm{P}=0.006)$ and $\mathrm{OS}(\mathrm{HR}, 2.504$; $95 \% \mathrm{CI}, 1.336-$ 4.499; $\mathrm{P}=0.005)$ in patients who had undergone hepatic resection for HCC (3).

Sarcopenia is a degenerative loss of skeletal muscle mass and strength. The cut-off value for sarcopenia using the SMI by computed tomography measurement in not yet well established, and there is no defined value. We previously showed that sarcopenia was an unfavorable factor for OS in patients who had undergone hepatic resection for HCC $(4,5)$. We defined sarcopenia as an SMI of $<43.75 \mathrm{~cm}^{2} / \mathrm{m}^{2}$ for male patients and $<41.10 \mathrm{~cm}^{2} / \mathrm{m}^{2}$ for female patients; in total, 75 of 190 (39.4\%) patients who had undergone hepatic resection for HCC were defined as having sarcopenia (5). In a recent study using the Japan Society of Hepatology guidelines for sarcopenia in patients with liver disease, the 
cutoff values of the SMI were $42 \mathrm{~cm}^{2} / \mathrm{m}^{2}$ for male patients and $38 \mathrm{~cm}^{2} / \mathrm{m}^{2}$ for female patients (6). Hamaguchi et al. defined sarcopenia as an SMI of $<40.31 \mathrm{~cm}^{2} / \mathrm{m}^{2}$ in male patients and $<30.88 \mathrm{~cm}^{2} / \mathrm{m}^{2}$ in female patients among healthy donors for living-donor liver transplantation. Their cutoff value for female patients was lower than that in the other study; thus, the proportion of patients with sarcopenia was lower in their study.

Obesity and its related non-alcoholic fatty liver disease are considered to be important causative factors in hepatocellular carcinogenesis. However, the effect of obesity on surgical outcomes in patients with HCC is controversial. Obesity is defined by the body mass index (BMI) or visceral fat area. We previously showed that a BMI of $\geq 25 \mathrm{~kg} / \mathrm{m}^{2}$ was a more favorable prognostic factor for RFS and OS than a BMI of $<25 \mathrm{~kg} / \mathrm{m}^{2}$ in Japanese patients who had undergone hepatic resection for HCC (7). A Taiwanese group reported that patients with HCC who had a low preoperative BMI of $<25 \mathrm{~kg} / \mathrm{m}^{2}$ exhibited lower RFS and OS rates after curative hepatic resection, and a low preoperative serum cholesterol level in patients with a BMI $<25 \mathrm{~kg} / \mathrm{m}^{2}$ could be an important contributor to the poor clinical prognosis (8). A propensity score-matched analysis of Chinese patients showed that obesity, defined as a BMI of $\geq 25 \mathrm{~kg} / \mathrm{m}^{2}$, did not influence outcomes in patients who had undergone hepatic resection for HCC (9). Cutoff values for the visceral fat area have been defined as $103 \mathrm{~cm}^{2}$ for male patients and $69 \mathrm{~cm}^{2}$ for female patients and are recognized as measures of metabolic abnormalities in Japan (10). Using these cutoff values, we previously showed that patients with a large visceral fat area had a significantly better prognosis than those with a small visceral fat area, and there was a significant association between the BMI and visceral fat area (5). Similar data using the same cutoff values have been reported by Higashi et al. (11). Hamaguchi et al. (12) defined obesity as a visceral fat area of $\geq 100 \mathrm{~cm}^{2}$ alone in both sexes according to the criteria for obesity disease established by the Japan Society for the Study of Obesity. They showed that the visceral fat area differed significantly between male and female patients. The proportion of men with HCC is epidemiologically high. The cutoff value for the visceral fat area as an indicator of obesity in patients with HCC should be set separately for men and women to avoid being affected by this bias.

Although obesity did not seem to be a poor prognostic indicator for patients with HCC as mentioned above, the authors of this study showed that sarcopenic obesity was the worst prognostic indicator after hepatic resection among the four categories of patients. They also found that the hazard ratios for the risk of death and HCC recurrence in patients with sarcopenic obesity were higher than those in patients with sarcopenia. Sarcopenic obesity might be superior to sarcopenia as a predictive indicator in patients who have undergone hepatic resection for HCC. Further research on this issue is necessary. The European Society for Clinical Nutrition and Metabolism and the European Association for the Study of Obesity recognize that sarcopenic obesity is defined as obesity with an altered body composition caused by low skeletal muscle mass and strength, and should be a priority for researchers and clinicians (13). Sarcopenic obesity assessment should be incorporated for patients undergoing hepatic resection for HCC. In addition, a worldwide consensus on an assessment of sarcopenic obesity that is applicable for each country should be developed. Multicenter prospective registries should be designed to establish the optimal cutoff values of sarcopenic obesity in patients with HCC.

\section{Acknowledgments}

We thank Cathel Kerr, BSc, PhD, and Angela Morben, DVM, ELS, from Edanz Group (www.edanzediting.com/ac), for editing a draft of this manuscript.

Funding: This study was supported by the following grant: JSPS KAKENHI, a Grant-in-Aid from the Ministry of Health, Labour and Welfare, Japan (JP-19K09198). The funding sources had no role in the collection, analysis, or interpretation of the data, or in the decision to submit the article for publication.

\section{Footnote}

Conflicts of Interest: All authors have completed the ICMJE uniform disclosure form (available at https://hbsn. amegroups.com/article/view/10.21037/hbsn.2019.09.14/coif). The authors have no conflicts of interest to declare.

Ethical Statement: The authors are accountable for all aspects of the work in ensuring that questions related to the accuracy or integrity of any part of the work are appropriately investigated and resolved.

Open Access Statement: This is an Open Access article distributed in accordance with the Creative Commons Attribution-NonCommercial-NoDerivs 4.0 International License (CC BY-NC-ND 4.0), which permits the non- 
commercial replication and distribution of the article with the strict proviso that no changes or edits are made and the original work is properly cited (including links to both the formal publication through the relevant DOI and the license). See: https://creativecommons.org/licenses/by-ncnd $/ 4.0 \%$.

\section{References}

1. Global Burden of Disease Liver Cancer Collaboration, Akinyemiju T, Abera S, et al. The Burden of Primary Liver Cancer and Underlying Etiologies From 1990 to 2015 at the Global, Regional, and National Level: Results From the Global Burden of Disease Study 2015. JAMA Oncol 2017;3:1683-91.

2. Itoh $S$, Yugawa $K$, Shimokawa $M$, et al. Prognostic significance of inflammatory biomarkers in hepatocellular carcinoma following hepatic resection. BJS Open 2019;3:500-8.

3. Kobayashi A, Kaido T, Hamaguchi Y, et al. Impact of Sarcopenic Obesity on Outcomes in Patients Undergoing Hepatectomy for Hepatocellular Carcinoma. Ann Surg 2019;269:924-31.

4. Harimoto N, Shirabe K, Yamashita YI, et al. Sarcopenia as a predictor of prognosis in patients following hepatectomy for hepatocellular carcinoma. Br J Surg 2013;100:1523-30.

5. Itoh S, Shirabe K, Matsumoto Y, et al. Effect of body composition on outcomes after hepatic resection for hepatocellular carcinoma. Ann Surg Oncol 2014;21:3063-8.

6. Nishikawa H, Shiraki M, Hiramatsu A, et al. Japan Society of Hepatology guidelines for sarcopenia in liver disease

Cite this article as: Itoh S, Yoshizumi T, Mori M. Is sarcopenic obesity superior to sarcopenia as a predicting indicator in patients with hepatocellular carcinoma following hepatic resection? HepatoBiliary Surg Nutr 2020;9(2):202-204. doi: 10.21037/hbsn.2019.09.14 (1st edition): Recommendation from the working group for creation of sarcopenia assessment criteria. Hepatol Res 2016;46:951-63.

7. Itoh S, Ikeda Y, Kawanaka H, et al. The effect of overweight status on the short-term and 20-y outcomes after hepatic resection in patients with hepatocellular carcinoma. J Surg Res 2012;178:640-5.

8. Lee YL, Li WC, Tsai TH, et al. Body mass index and cholesterol level predict surgical outcome in patients with hepatocellular carcinoma in Taiwan - a cohort study. Oncotarget 2016;7:22948-59.

9. Guo Z, Zhang J, Jiang JH, et al. Obesity Does Not Influence Outcomes in Hepatocellular Carcinoma Patients following Curative Hepatectomy. PLoS One 2015;10:e125649.

10. Kashihara H, Lee JS, Kawakubo K, et al. Criteria of waist circumference according to computed tomographymeasured visceral fat area and the clustering of cardiovascular risk factors. Circ J 2009;73:1881-6.

11. Higashi T, Hayashi H, Kaida T, et al. Prognostic Impact of Visceral Fat Amount and Branched-Chain Amino Acids (BCAA) in Hepatocellular Carcinoma. Ann Surg Oncol 2015;22 Suppl 3:S1041-7.

12. Examination Committee of Criteria for 'Obesity Disease' in Japan; Japan Society for the Study of Obesity. New criteria for "obesity disease" in Japan. Circ J 2002;66:987-92.

13. Barazzoni R, Bischoff S, Boirie Y, et al. Sarcopenic Obesity: Time to Meet the Challenge. Obes Facts 2018;11:294-305. 